\title{
$\mathrm{VII} \mathrm{CINCCl}$
}

VII Colóquio internacional sobre Comércio e Cidade

Fortaleza, 03 a 07 de Novembro de 2020

\section{A produção de uma cidade monofuncional}

The production of a monofunctional city.

La producción de una ciudad monofuncional.

SÁ, Viviane Regina Costa; Doutora; Universidade Federal de Alagoas (UFAL) vivianercosta@gmail.com

\section{Resumo}

Este artigo apresenta uma crítica do que foi proposto enquanto áreas comerciais por ação empreendedora pública e privada nas concepções de empreendimentos residenciais na cidade de Maceió/AL. O objetivo deste estudo foi identificar como as áreas comerciais e de serviços foram demarcadas, projetadas e instaladas no espaço urbano e quais eram as práticas adotadas nos projetos de parcelamento do solo e se estas foram próprias de uma determinada época ou se ainda se repercutem na atual forma de conceber o espaço da cidade. O estudo foi desenvolvido procurando seguir uma linha de tempo agrupando os projetos por décadas, o que nos permitiu verificar como se consolidava o espaço urbano e o que estava posto no entorno próximo dos empreendimentos, com o objetivo de averiguar se a existência de ocupação vizinha interferia na produção de espaços comerciais.

Palavras-chave: Áreas comerciais. Empreendimentos residenciais. Monofuncional.

\section{The production of a monofunctional city.}

\section{Abstract}

This article presents a critique of what was proposed as commercial areas by public and private entrepreneurial action in the conceptions of residential enterprises in the city of Maceió / AL. The objective of this study was to identify how the commercial and service areas were demarcated, projected and installed in the urban space and what were the practices adopted in the land parceling projects and whether they were specific to a certain time or if they still have repercussions in the current one way of conceiving the city space. The study was developed seeking to follow a timeline grouping the projects for decades, which allowed us to verify how the urban space was consolidated and what was placed in the surroundings close to the developments, with the objective of verifying whether the existence of neighboring occupation interfered in the production of commercial spaces.

Keywords: Commercial areas. Residential developments. Monofunctional. 


\section{$\mathrm{VII} \mathrm{CINCCl}$}

VII Colóquio internacional sobre Comércio e Cidade

Fortaleza, 03 a 07 de Novembro de 2020

\section{La producción de una ciudad monofuncional.}

\section{Resumen}

Este artículo presenta una crítica de lo que se propuso como áreas comerciales por la acción empresarial pública y privada en las concepciones de empresas residenciales en la ciudad de Maceió / AL. El objetivo de este estudio fue identificar cómo se delimitaron, proyectaron e instalaron las áreas comerciales y de servicio en el espacio urbano y cuáles fueron las prácticas adoptadas en los proyectos de parcelación de terrenos y si fueron específicos en un momento determinado o si aún tienen repercusiones en el actual. forma de concebir el espacio de la ciudad. El estudio se desarrolló buscando seguir una línea de tiempo que agrupara los proyectos durante décadas, lo que nos permitió verificar cómo se consolidó el espacio urbano y qué se colocó en los alrededores cercanos a los desarrollos, con el objetivo de verificar si la existencia de la ocupación vecina interfería en la producción de espacios comerciales.

Palabras clave: Zonas comerciales. Desarrollos residenciales. Monofuncional. 


\section{0 comércio e a produção de espaços habitacionais.}

Desde o ano de 2003, o grupo de pesquisa MEP - Morfologia dos Espaços de Uso Público -, da Faculdade de Arquitetura e Urbanismo da Universidade Federal de Alagoas, tem analisado os tecidos urbanos legais propostos para a cidade de Maceió/AL e que estão registrados na Prefeitura Municipal de Maceió, desde o ano de 1945. Acessando os desenhos originais dos empreendimentos habitacionais, conseguimos identificar os principais elementos componentes, morfologia, dimensões e levantamos hipóteses sobre a concepção de cidade presente em cada um deles. Entre as informações coletadas, um aspecto chamou a atenção: a pequena ou quase nula destinação de áreas para a atividade comercial.

Na segunda metade do século XX, entre os anos de 1945 (data do primeiro registro de parcelamento do solo encontrado nos arquivos da Prefeitura Municipal de Maceió) e 1999, foram registrados 561 projetos e destes apenas 23 apresentavam em seus desenhos originais, proposta de inserção de área comercial. Destes projetos, 15 eram conjuntos habitacionais, 7 loteamentos e 1 condomínio.

Nos primeiros quinze anos do século XXI (2000-2015) foram registrados mais 173 projetos de empreendimentos habitacionais, dos quais apenas 03 continham, em seus desenhos originais, espaços destinados à implantação da atividade comercial, 2 condomínios e 1 conjunto.

Sintetizando: em um período de setenta anos de produção da cidade (1945 2015 ), de 657 projetos, apenas 3,95\% (26 projetos) apresentaram proposta de destinação de espaços para instalação do comércio e dos serviços no interior dos residenciais - 16 conjuntos, 7 loteamentos e 3 condomínios.

Pergunta-se: por que o comércio não é um elemento frequente nos programas urbanísticos dos empreendimentos habitacionais? Por que não há exigência normativa de destinação de percentual da área total do empreendimento para atividade terciária, assim como é feito para equipamentos urbanos e comunitários? Por que não há interesse dos empreendedores em inserir a atividade comercial nos desenhos dos habitacionais?

Apesar do pequeno número de projetos com espaço para atividade terciária, o comércio e os serviços terminam instalando-se nos empreendimentos, independente de terem sido planejados ou não, independente da tipologia urbanística do empreendimento habitacional (loteamentos, conjuntos habitacionais ou condomínios), independente do perfil de renda familiar a que se destina o empreendimento.

A ausência da atividade comercial no interior dos empreendimentos habitacionais pode ser interpretada como um reflexo do modo como o "habitar" tem sido traduzido nos desenhos urbanos, o qual se resume, na maior parte dos casos, à oferta da unidade residencial, distante dos principais centros de comércio e serviços e desprovido de abastecimento de produtos de primeira necessidade. Por essa razão, o uso do solo pensado quase exclusivamente à atividade residencial, gradativamente, vai sendo substituído pelos usos que complementam a dinâmica da vida urbana.

Questionamos, portanto, de que modo a atividade comercial é inserida nos empreendimentos habitacionais, uma vez que previsto ou não, o comércio tende a se instalar, tanto pela iniciativa dos empreendedores, inserindo-o na proposta original do projeto, mas sobretudo pela iniciativa dos moradores, movidos pela 
necessidade de gerar renda, pela oportunidade em montar seu próprio estabelecimento, dada a demanda existente, e para encurtar a distância às formas de abastecimento básico que são próprias do dia-a-dia.

Em se tratando de produção de espaços destinados à atividade comercial, os projetos urbanísticos de conjuntos habitacionais populares foram os que apresentaram um número maior de empreendimentos. Entre os anos de 1945 e 2015, dos 657, apenas 16 conjuntos, 7 loteamentos e 3 condomínios apresentaram proposta de destinação de espaços para instalação do comércio e dos serviços.

O pequeno número de projetos com destinação de espaços para uso comercial (apenas 3,95\%) enfatiza o caráter monofuncional das propostas de empreendimentos habitacionais que foram concebidos para a cidade de Maceió. Obviamente não podemos desconsiderar, na caracterização destes empreendimentos, os espaços destinados aos equipamentos urbanos e comunitários, presentes em alguns projetos, que complementam o uso residencial. Lembrando que não é a previsão dos equipamentos que asseguram a sua instalação. Mas destacamos aqui aquilo que está posto enquanto proposta de novos tecidos habitacionais.

Além destes espaços previstos nos projetos com uso futuro especificado, o autor André Prado (2016:270), em seu estudo sobre os conjuntos habitacionais populares, destaca a importância de se ter áreas livres, inclusive livres de funções pré-determinadas, classificadas por ele como espaços "sem-função" ou "desfuncionalizados", abertos às intervenções dos próprios moradores de acordo com aquilo que julgarem necessário. O autor chama a atenção para essa questão pela prática imobiliária mercadológica corriqueira de utilização de todo o espaço da gleba pelo uso exclusivamente residencial, de modo que o retorno financeiro esteja assegurado na comercialização do maior número possível de unidades habitacionais, sem que seja levada em conta a possibilidade de intervenções futuras em áreas livres:

\footnotetext{
Dificilmente um projeto urbanístico preso a essa lógica (ainda que inconscientemente) deixaria espaços abertos, "sem-função". Criar espaços vazios para que as coisas possam acontecer livremente no futuro não garante que venham de fato a acontecer. Mas não criar esses espaços vazios certamente impede que aconteçam (grifo nosso) (PRADO, 2016:271).
}

$\mathrm{Na}$ análise que fizemos nos projetos com área comercial prevista na proposta original, verificamos também que a presença destes espaços não inibe a instalação do comércio em outros pontos do empreendimento, bem como no interior da residência, e ainda a transformação das unidades residenciais em estabelecimentos comerciais.

É fato que, à medida que o uso residencial se afasta das áreas mais centrais das cidades, das áreas abastecedoras da vida urbana e onde concentra a maior parte dos comércios e dos serviços, termina por levar consigo e atrair relocações e expressões dessas atividades. Como destaca Milton Santos:

\footnotetext{
A localização dos pequenos comércios nos bairros facilita, sobretudo, a vida das populações de baixo nível de consumo, que na maioria dos casos, em não dispondo de automóveis particulares e restando pouco dinheiro para o transporte coletivo, deixam de abastecer-se frequentemente nos grandes comércios modernos, que geralmente situam-se nas áreas centrais das cidades ou nos seus arredores, ao longo de importantes vias de circulação de veículos (SANTOS, 1979:168).
} 
Sobre a proposta de destinação de área para atividade comercial, identificamos três situações distintas nos projetos: (i) instalação da atividade comercial em localização prevista no projeto, com a posterior constituição de uma centralidade no interior no empreendimento; (ii) instalação da atividade comercial em área distinta do que foi previsto no projeto; e (iii) área destinada à atividade terciária sem estar ocupada ou com uso diferente do planejado.

\section{A malha urbana monofuncional que se formou durante meio século (1945-2000)}

A partir do ano de 1945, data em que encontramos o primeiro registro de parcelamento do solo, a formação do espaço urbano de Maceió foi fortemente marcado pela expansão do tecido urbano para além da região do bairro do Centro, através da localização dos novos empreendimentos ao longo de um importante vetor de crescimento da época, a Avenida Fernandes Lima, localizado na região de Tabuleiros. Entre os anos de 1945 e 1960, foram registrados 125 projetos de parcelamento do solo: 120 loteamentos, 03 desmembramentos e 02 conjuntos habitacionais (MACEIÓ, 2000 - Cadastro dos Parcelamentos de Maceió, Secretaria Municipal de Controle e Convívio Urbano).

Apesar do grande número de projetos registrados no período, nas propostas dos empreendimentos não havia uma diferenciação de usos dos lotes ou das unidades, prevalecendo o uso residencial. É certo que, como a maior produção de novos espaços urbanos aconteceu na forma de loteamentos, a edificação a ser construída no novo lote poderia ter um uso diferente do inicialmente previsto.

Neste intervalo de quinze anos (1945-1960), foi encontrado apenas um registro de projeto (localizado nos arquivos da prefeitura) com a proposta de espaço para o comércio. Trata-se do projeto de loteamento denominado Unidade de Vizinhança do Sítio Goiabeiras, registrado no ano de 1957, localizado no bairro de Santa Lúcia, na região de Tabuleiros, a $10 \mathrm{~km}$ de distância do bairro do Centro, composto por 231 lotes, um parque e uma quadra de uso misto. Na descrição do desenho, essa quadra seria destinada à instalação de mercadinhos e à construção de uma escola primária.

Considerando que nesse período as atividades econômicas, administrativas e de lazer estavam concentradas na região central, as propostas de projetos destinados exclusivamente ao uso residencial iniciava uma tendência confirmada nos períodos seguintes: empreendimentos de caráter monofuncional que, apesar de expandir a ocupação da cidade para regiões mais periféricas, em seus desenhos estava contemplada a formação de empreendimentos dormitórios, desprovidos de atividades distintas de residencial. A cidade periférica era planejada sem a preocupação de oferta de comércio e serviços que, pelo menos, atendessem as necessidades diárias.

Apesar de identificarmos esta possível intenção, atualmente, a área destinada à implantação dos equipamentos encontra-se ocupada por residências e a escola não foi instalada.

Ao mesmo tempo que destacamos a proposta do loteamento com previsão de área para uso comercial, enfatizamos o grande número de empreendimentos que marcavam o início da ocupação na área de Tabuleiros sendo caracterizados unicamente pelo uso residencial. Questionamos aqui como se daria o 
abastecimento dos futuros moradores. É fato que, à medida que as unidades fossem comercializadas e ocupadas, a própria demanda poderia suscitar iniciativas de instalação de pequenos comércios, sobretudo com a oferta de material de construção, haja visto o grande número de lotes à venda na época e que gerariam novas construções. Porém, destacamos também, que a atividade terciária, juntamente com a institucional, poderia estar presente no programa urbanístico destes empreendimentos como instrumentos de expansão do tecido urbano, numa forma de levar, antecipadamente, para regiões periféricas, os usos concentrados até então na região central. Essa medida poderia ajudar no crescimento ordenado da cidade, sobretudo sob dois aspectos: mobilidade e formação de centralidades. A definição antecipada dos usos ajudaria na definição de um sistema viário compatível com as atividades a serem instaladas e, consequentemente, com a função que a via desempenharia na cidade. Porém, esta estratégia não esteve presente na maior parte dos empreendimentos registrados na época. A coordenação do processo de urbanização num nível mais complexo de idealização não tem sido uma característica das administrações municipais que se sucedem. Alguma concepção mais próxima desta será a institucionalização do conceito de "Corredor de Atividades Múltiplas" (CAM), final do século XX.

$\mathrm{Na}$ década seguinte, entre os anos de 1960 e 1970, a direção da Planície Litorânea Norte passou a ser alvo dos empreendimentos urbanos e grande parte do território litorâneo, até então ocupada por areais e coqueirais, começou a ceder lugar para os projetos de loteamentos destinados às habitações, apesar de ainda ser a área de tabuleiro, a localidade onde os projetos ocorriam em maior número. Nesse período foram registrados 115 novos empreendimentos de projetos de parcelamento do solo na Prefeitura de Maceió, dos quais 75\% eram loteamentos (84), 18\% desmembramentos (15) e 7\% conjuntos habitacionais (5). Deste total, 104 foram encontrados nos arquivos da SMCCU e fizeram parte da análise: 84 loteamentos, 18 desmembramentos e 05 conjuntos habitacionais.

Durante este período, dois outros eixos viários pareciam desempenhar o mesmo papel de vetores de expansão urbana que o exercido pela Avenida Fernandes Lima nos anos anteriores, agora na área da Planície Litorânea: Avenida Álvaro Otacílio (antiga Avenida Deputado José Lages - via da orla marítima) e Gustavo Paiva. Estas duas avenidas, como vetores de expansão do tecido urbano, direcionavam a ocupação no sentido do litoral norte e a maior parte dos empreendimentos legais aprovados no período localizados nesta área estendia suas glebas perpendiculares a estas duas vias, configurando-se como parcelamentos lineares em faixas de terra compridas e estreitas. Dos projetos registrados e analisados, apenas um empreendimento apresentava área de comércio na proposta original. Trata-se do Conjunto Jardim Beira Mar (Figura 1), da Companhia de Habitação Popular de Alagoas - COHAB, registrado no ano de 1968, localizado na região de Planície Litorânea, numa área de expansão e distante cerca de $5 \mathrm{~km}$ do bairro do Centro, com 428 unidades habitacionais. Esse período marcou o início das atividades do Banco Nacional de Habitação - BNH - na cidade de Maceió com a construção de grandes conjuntos habitacionais. 


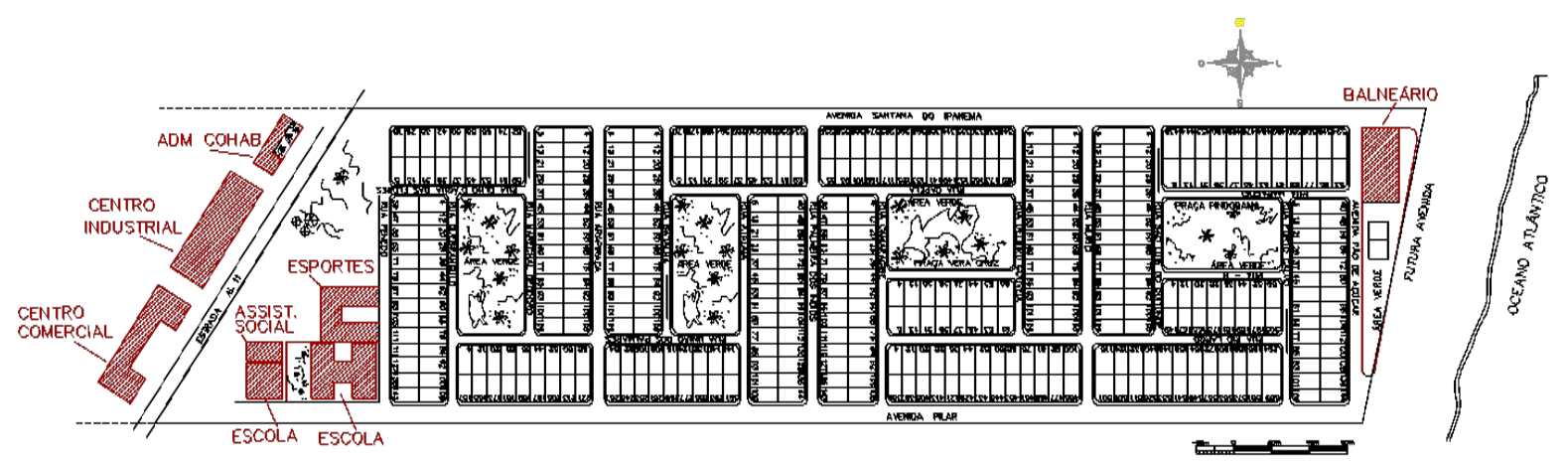

Figura 1: Conjunto Habitacional Jardim Beira Mar, 1968 - COHAB - Detalhe da área comercial.

Fonte: Projeto original recuperado através de desenho digital pelo MEP - Núcleo de Estudos Morfologia dos Espaços Públicos - MEP/FAU/UFAL.

Além do centro comercial, no projeto estava previsto um centro industrial, uma área administrativa da $\mathrm{COHAB}$, um espaço para escola, uma área para esportes, outra destinada à assistência social e um balneário. É importante destacar que naquele momento, a ocupação da região da Planície Norte também estava se iniciando.

No conjunto Jardim Beira Mar nenhum dos espaços projetados para atividades de complementação do uso residencial foi ocupado. Na porção destinada aos centros industrial e comercial e à área administrativa da COHAB foi implantado um conjunto residencial. Nas áreas destinadas à escola e aos esportes, atualmente, está instalado um posto de gasolina.

No período seguinte, na década de 1970, a localização dos projetos reforçou a ocupação da área de Planície Litorânea Norte, iniciada nos anos anteriores, bem como a ocupação da região de Tabuleiros, que ofertava grandes estoques de glebas afastadas do Centro da cidade de Maceió, localizadas às margens da rodovia BR104, tendo como facilitador de acesso o eixo da Avenida Fernandes Lima, que permitia os deslocamentos entre as duas regiões geográficas (Planície e Tabuleiros). Naquele período, foram registrados 104 novos projetos de parcelamento do solo. Desse total, foram localizados 96 projetos nos arquivos da prefeitura, dos quais 54 eram loteamentos, 24 desmembramentos e 16 conjuntos habitacionais.

Na área de Tabuleiro a ocupação foi intensificada, principalmente, com a construção dos conjuntos habitacionais, como resultado das atividades das companhias estatais de habitação popular (COHAB, IPASEAL, INOCOOP).

Estes conjuntos foram implantados em áreas mais periféricas e desconectados do tecido urbano existente criando-se uma grande extensão de espaços vazios entre as áreas mais ocupadas e estas novas localizações. Certamente, os pontos escolhidos pelas companhias financiadoras agregavam a disponibilidade de espaço e o baixo preço da terra.

Nos empreendimentos dessa época, houve um aumento no número de projetos com áreas comerciais. Nas décadas anteriores, nos desenhos analisados, foram encontradas apenas dois (um em cada década) e ao longo da década de 70, onze desenhos apresentavam áreas com descrição de uso para o comércio e/ou serviços em suas propostas originais. Os conjuntos habitacionais foram os que apresentaram maior número de projetos com área comercial prevista: dos 54 loteamentos registrados, apenas 5 apresentavam este tipo de área, enquanto que 
dos 16 conjuntos, 6 tinham espaços para o uso terciário. Analisando os desenhos dos empreendimentos, a designação dos espaços de comércio e serviços nos projetos aparece tanto com uma indicação geral de uso, normalmente com a inscrição "área comercial", quanto com sugestões específicas dos estabelecimentos que poderiam ser instalados. Os registros mais comuns encontrados são: Lotes comerciais; Comércio; Centro; Centro e feira; Feira livre; Comércio local.

Desse período destacamos dois empreendimentos: (i) Conjunto Eustáquio Gomes de Melo (Figura 2), no qual se verifica a instalação de atividade comercial em área diferente do que foi previsto e que se consolidou como importante centralidade local com grande concentração de estabelecimentos comerciais; e (ii) o Loteamento Stella Maris (Figura 3), com ocupação da área prevista do projeto e consolidação de importante centralidade em nível de cidade, pelo tipo e diversidade de atividades.

Entre os anos de 1980 e 1990, destacadamente, a área de maior e mais intensa ocupação urbana foi a região de Tabuleiros, aparecendo poucos empreendimentos localizados nas regiões de Planície tanto Lagunar como Litorânea Os bairros do Feitosa, Gruta de Lourdes e Barro Duro, ocupados nos anos 70 , porém ainda sem muita expressão na dinâmica urbana de Maceió, ganharam novos empreendimentos, destacando-se os conjuntos habitacionais, financiados pelas companhias estatais de habitação popular, como mencionado anteriormente.

Com a conclusão de parte do projeto de construção da Via de Acesso ao Porto sobre o Tabuleiro, atual Via Expressa, as áreas localizadas às suas margens passaram a se constituir como novos pontos de localização dos empreendimentos imobiliários, sobretudo Serraria e Antares, bairros que ainda permaneciam com uma grande quantidade de glebas vazias e que se apresentavam, no momento, como nova frente de expansão urbana.

Nesse período foram registrados 127 projetos de parcelamento do solo, dos quais 45 eram loteamentos, 31 desmembramentos, 43 conjuntos habitacionais e 8 condomínios. Do total de projetos registrados, foram localizados 97 desenhos originais. Dos projetos analisados, apenas $8,2 \%$ apresentavam, em suas propostas originais, espaços destinados à atividade comercial, dos quais 1 era loteamento, 8 conjuntos habitacionais e 1 condomínio. 


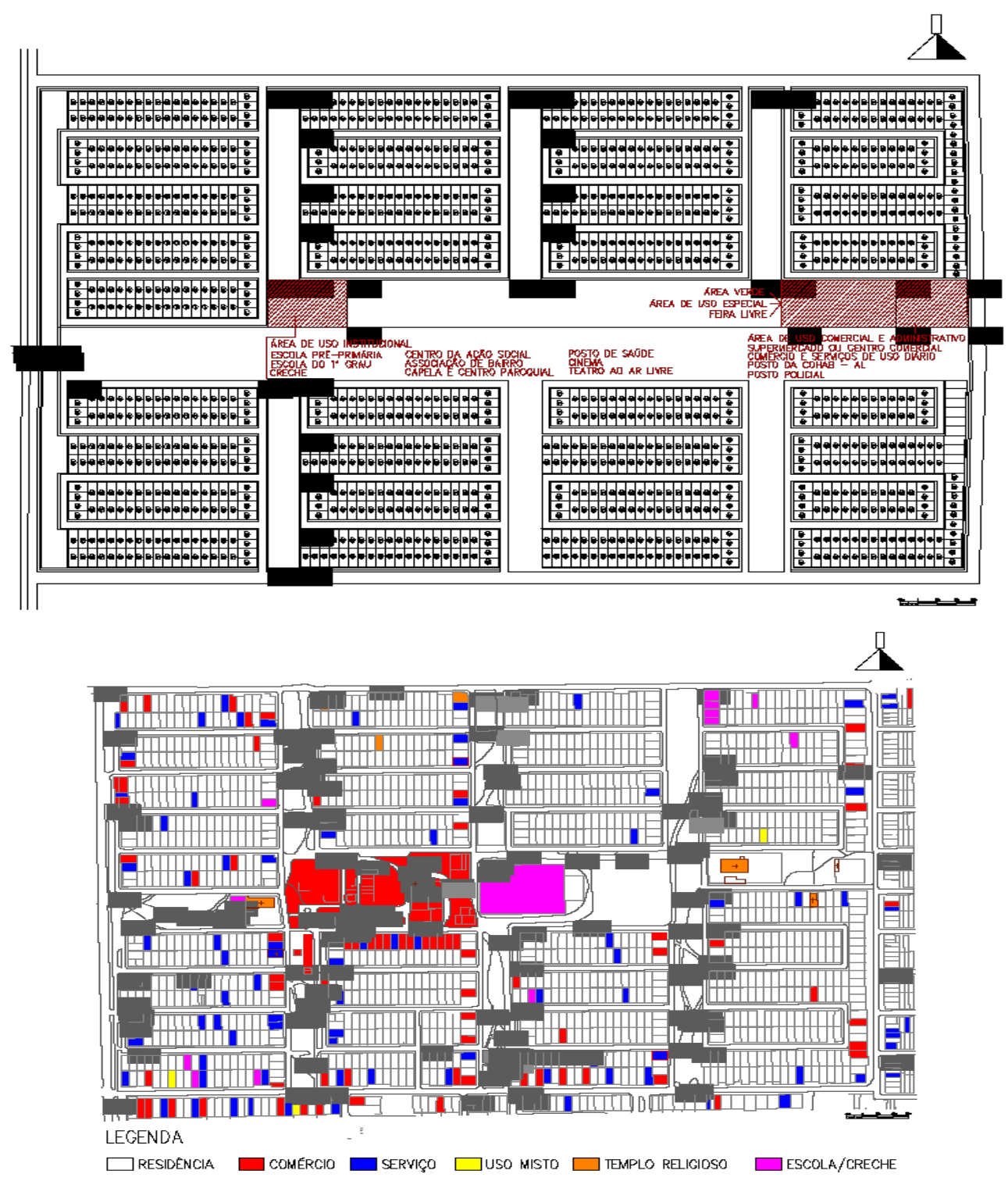

Figura 2: Projeto original Conjunto Graciliano Ramos, 1988 - Detalhe da área comercial (acima) e Uso do Solo atual, 2017 (abaixo)

Fonte: Projeto original recuperado através de desenho digital pelo Núcleo de Estudos Morfologia dos Espaços Públicos - MEP/FAU/UFAL.

Nos empreendimentos deste período, destacamos o projeto do Conjunto Graciliano Ramos (Figura 3), o qual evidencia o modo como a atividade comercial pode se instalar em pontos diversos do que foi previsto no desenho original. 


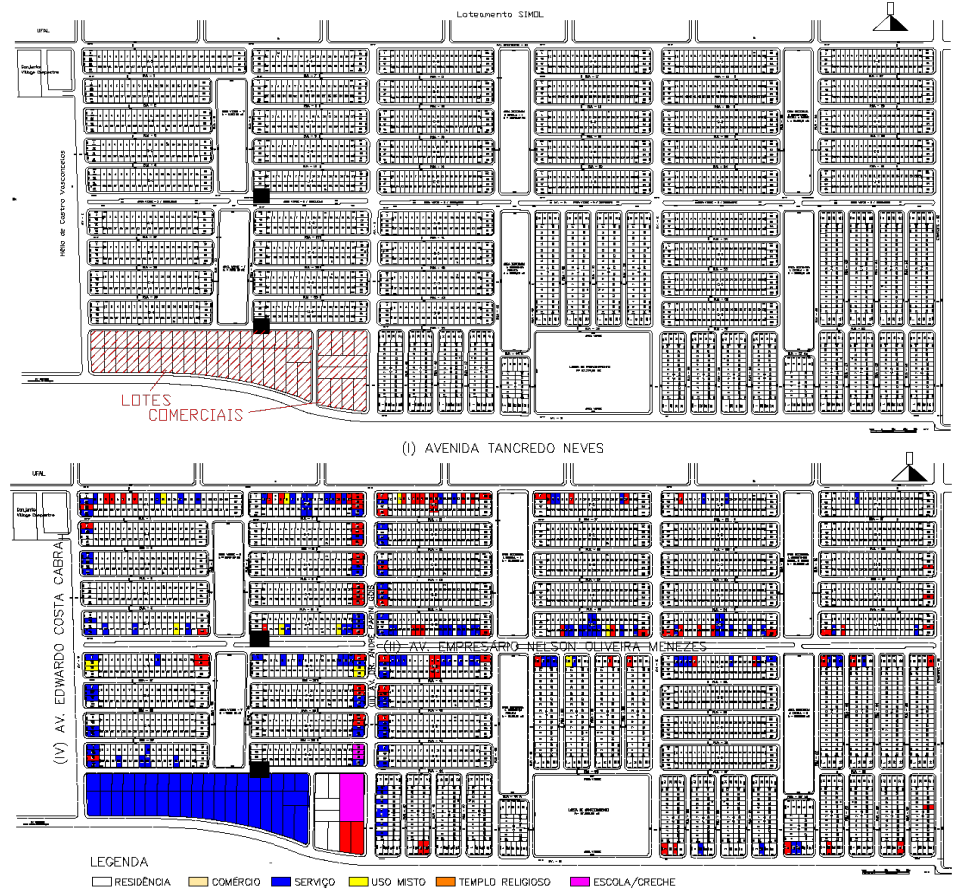

Figura 3: Projeto original Conjunto Graciliano Ramos, 1988 - Detalhe da área comercial (acima) e Uso do Solo atual, 2017 (abaixo)

Fonte: Projeto original recuperado através de desenho digital pelo Núcleo de Estudos Morfologia dos Espaços Públicos - MEP/FAU/UFAL.

Entre os anos de 1990 e 2000, foram registrados 90 projetos, dos quais 44 eram loteamentos, 13 desmembramentos, 25 conjuntos habitacionais e 8 condomínios. Do total, foram localizados 67 projetos, dos quais nenhum apresentava área comercial em sua proposta original.

Durante a última década do século $\mathrm{XX}$, a continuidade do processo de formação do espaço urbano de Maceió por parte dos empreendimentos habitacionais se deu a partir da ocupação de terrenos intersticiais sobretudo na região de Tabuleiros. Ainda em maior número estavam os loteamentos, seguidos dos conjuntos habitacionais, que notadamente neste período não trouxeram contribuições significativas em termos de diversificação do uso do solo, prevalecendo o perfil monofuncional dos empreendimentos. É certo que neste período, muito do espaço projetado exclusivamente para o uso residencial, já tinha o seu perfil modificado e muitos pontos de comércio e serviços já estavam instalados, o que possivelmente pode ter contribuído para o pequeno número de projetos com área comercial. Entretanto, mais uma vez ressaltamos o tipo de produção citadina que desconsidera as potencialidades inerentes ao comércio, que torna possível, sobretudo, a existência da cidade. Como destaca Teresa Salgueiro (SALGUEIRO, 1996:31): "não deixa de ser estranha a fraca importância assumida pelo planejamento comercial no conjunto do ordenamento do território, apesar do generalizado reconhecimento da importância do comércio para as cidades, elevado muitas vezes à categoria de função criadora, animadora e imagética".

\section{Um século novo, e a monofuncionalidade permanece (2000-2015)}


No estudo dos primeiros quinze anos do Século $X X$, dividimos os empreendimentos registrados na Prefeitura de Maceió em dois momentos: o primeiro, que corresponde ao intervalo entre os anos de 2000 e 2008 e, o segundo, entre os anos de 2009 e 2015. A separação entre os dois períodos justifica-se por dois motivos: (i) em se tratando de produção resultante do Programa Minha Casa Minha Vida, consideramos a data de lançamento deste programa (março/2009) e o último ano de coleta de dados (2015), e por isso preferimos destacar, em números, a contribuição dos projetos na produção do espaço da cidade.

Entre os anos de 2000 e 2008, foram registrados 86 projetos, e pela primeira vez, o número de condomínios foi maior que o de loteamentos e de conjuntos habitacionais. Esse tipo de empreendimento e a elevação significativa de suas propostas aumenta a discussão sobre a inserção da atividade comercial em empreendimentos habitacionais. Isso porque nos loteamentos, o comprador do lote poderá construir uma edificação destinada à implantação de uma atividade econômica (com exceção dos lugares não permitidos por lei - mas não esqueçamos que nem sempre ela se faz efetiva!). Da mesma forma, como verificamos, nos conjuntos habitacionais as unidades residenciais podem, gradativamente, ter o seu perfil modificado, bem como alterada a sua estrutura original para instalação da atividade comercial e ou de serviço. Quando falamos de condomínios, associamos diretamente à existência de instrumentos reguladores que controlam o uso do solo, os quais, na maioria dos casos, proíbem a instalação do comércio no interior das residências, assim como nos espaços de uso comum. E sobre este aspecto, questionamos: como se dá o abastecimento da população residente destes empreendimentos? Na vizinhança, por certo. Mas, se há um aumento expressivo no número de condomínios destinados apenas para o uso residencial, mais uma vez o urbanismo planejado da cidade deixa de oferecer espaços que garantam a diversidade de usos e minimizem os impactos dos inúmeros empreendimentos "dormitórios", que se esvaziam durante o dia e povoam-se apenas à noite após o encerramento das atividades econômicas e dos empregos em outras áreas da cidade.

Dos 86 empreendimentos registrados, foram encontrados nos arquivos da PMM, 62 projetos, dos quais apenas um apresentava área comercial na proposta original. Trata-se do Condomínio Theobaldo Barbosa, do Programa de Arrendamento Residencial (PAR), localizado às margens da BR-104, próximo aos Conjuntos Eustáquio Gomes e INOCOOP. No projeto do residencial foram destinados cinco espaços para a instalação de lojas comerciais, com 43,00 ${ }^{2}$ cada, voltados para área externa do condomínio (Figura 4). A proposta do empreendimento parece favorecer o abastecimento da população, com a possibilidade de instalação de estabelecimentos de pequeno porte. Esse projeto apresentava-se como um diferencial nos empreendimentos do PAR, uma vez que não era obrigatória a existência de área comercial nas propostas do Programa. É possível que a localização tenha contribuído para a inserção da atividade econômica, posto que os estabelecimentos comerciais de abastecimento diário só podiam ser encontrados nos conjuntos vizinhos. Entretanto, atualmente, os boxes destinados à atividade comercial não estão ocupados e encontram-se desativados. 


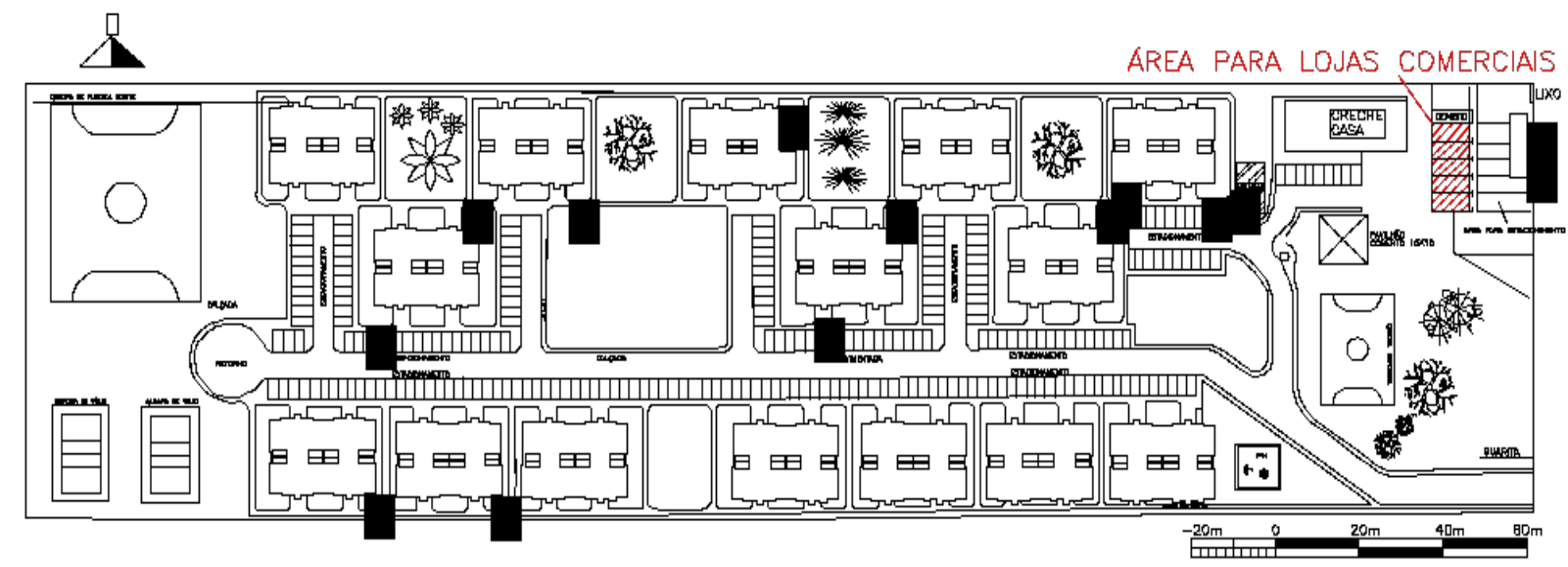

Figura 4: Condomínio Theobaldo Barbosa, 2002 - Detalhe da área comercial.

Fonte: Projeto original recuperado através de desenho digital pelo Núcleo de Estudos Morfologia dos Espaços Públicos - MEP/FAU/UFAL.

Nos anos seguintes, entre 2009 e 2015, o número de empreendimentos registrados como condomínios, mais uma vez, aumentou significativamente. No intervalo de seis anos foram implantados 70 empreendimentos do tipo condomínio, enquanto o número de conjuntos foi de 17. Destes empreendimentos, os projetos do Programa Minha Casa Minha Vida perfazem o número de 51 condomínios e 15 conjuntos. Ou seja, $75 \%$ dos projetos implantados na cidade de Maceió entre 2009 e 2015 foram do PMCMV. A expressiva quantidade de empreendimentos habitacionais implantados pelo programa em Maceió nos motivou a analisar que tipo de cidade estava desenhada nos projetos, cujas iniciativas partiam de dois patrocinadores distintos e com objetivos distintos: a pública e a privada. Fazer a crítica do que foi proposto para o espaço urbano de Maceió nos permite levantar questões sobre as concepções de tecido urbano que têm predominado no processo de planejamento de empreendimentos habitacionais, na maior parte dos casos, de caráter monofuncional, com uso exclusivamente residencial.

Dos 87 projetos registrados no período, apenas dois empreendimentos apresentavam área comercial nos desenhos originais. Trata-se do Condomínio Grand Jardim e do Conjunto Parque dos Caetés, ambos do Programa Minha Casa Minha Vida. Nos dois casos as áreas comerciais não foram instaladas, nem comercializadas e mantêm-se desocupadas.

Ao analisar o conjunto de empreendimentos do PMCMV, esperávamos encontrar mudanças significativas na forma de produzir o espaço da cidade, sobretudo nos aspectos relacionados à inserção da atividade comercial nos residenciais. Isso porque: (i) a maior parte dos projetos foram implantados em áreas periféricas, distantes até $17 \mathrm{~km}$ do bairro do Centro, que ainda é o principal ponto comercial e de abastecimento da cidade; (ii) os projetos de conjuntos habitacionais, destinados a famílias com renda de até três salários mínimos, foram objetos de uma política habitacional de relocação de assentamentos precários e em áreas de risco, e que deveriam oferecer às pessoas remanejadas o acesso à educação, saúde, lazer e abastecimento; (iii) pelo número de projetos de conjuntos habitacionais com área comercial nas décadas anteriores, também fruto de política habitacional, imaginávamos encontrar projetos com desenhos que inaugurassem uma nova maneira de conceber o espaço do habitar, com o uso residencial acrescido dos 
demais usos; e (iv) como foi grande a quantidade de empreendimentos do tipo condomínio, muitos construídos como um grande complexo habitacional no qual não se consegue distinguir início e fim de cada um, a acessibilidade ao comércio e aos serviços estaria assegurada se áreas destinadas à atividade terciária estivesse inserida nos projetos. Mas, no que conseguimos compreender da forma de produção da cidade do PMCMV, somos enfáticos em afirmar que ocorreu um retrocesso na qualidade do espaço urbano produzido, na qual o grande ditador das regras foi o capital privado, não obstante a maior parte dos projetos e o maior beneficiário da política foram as construtoras.

\section{Em síntese}

Na segunda metade do século XX e nos primeiros quinze anos do século XXI, a atividade comercial nos empreendimentos habitacionais não foi elemento condicionante na forma de conceber o espaço da cidade. Dos 734 projetos de parcelamento do solo registrados, apenas 26 (3,54\%) apresentavam área comercial em suas concepções originais, tendo como maior contribuição os projetos de conjuntos habitacionais - 16 projetos.

Nos desenhos dos conjuntos habitacionais observa-se a tentativa de criação de configurações urbanas que se aproximam das unidades de vizinhança, as quais, caracterizadas como uma área residencial que detém certa autonomia, apresentam em seu projeto, áreas destinadas à instalação de estabelecimentos de comércios e serviços que atendam as necessidades diárias dos residentes, principalmente do pequeno comércio como padaria, açougue, quitanda, mercado, entre outros. $\mathrm{E}$ como os conjuntos são quase sempre fruto de políticas habitacionais, os programas com usos diferenciados parecem indicar certas diferenças entre as iniciativas públicas e privadas na forma de conceber a cidade. Ainda que não possamos enfatizar as diferenças entre todos os empreendimentos e nem assegurar que a iniciativa pública oferece sempre as melhores concepções urbanas, haja visto o pequeno número de conjuntos habitacionais com área comercial e a praticamente nula existência nos empreendimentos do Programa Minha Casa Minha Vida.

É possível que nestes projetos estivesse refletida uma proposta de criação de espaços que pudessem proporcionar o convívio social, criando o lugar do encontro e da troca. As ações próprias da atividade comercial, a estocagem e a troca da moeda por produtos e serviços, permite, em paralelo, a troca de experiências e o contato pessoal. Considerando que os estabelecimentos presentes atenderiam, principalmente, as necessidades diárias, estes lugares teriam a possibilidade de se tornarem espaços de encontros diários, contribuindo para a formação de novas centralidades, tanto na escala do empreendimento, quanto do bairro e da cidade.

Das áreas comerciais previstas nos projetos de parcelamento do solo: (i) nem todas foram instaladas; (ii) algumas tiveram o uso original modificado; e (iii) outras foram de fato instaladas de acordo com o uso previsto.

Esse quadro de mudanças e permanências nos projetos originais revela que nem sempre no empreendimento em que está prevista a instalação de uma área comercial haverá a sua efetivação. $\mathrm{E}$, mesmo no caso das áreas comerciais projetadas sendo ocupadas, outras áreas do empreendimento também podem ganhar dinâmicas diferentes sobretudo de fluxo veicular e de pedestre e propiciar a instalação de atividades comerciais. Ou seja, prevista ou não, ocupando seu lugar originalmente concebido ou uma área distinta, a atividade comercial tende a emergir 
nos empreendimentos habitacionais. Quando enfatizamos a previsão do espaço destinado ao comércio nos projetos, estamos querendo discutir a forma de concepção da cidade que tem sido expressivamente marcada pelo caráter monofuncional. Em muitas discussões sobre a qualidade dos espaços produzidos a partir dos projetos habitacionais, veem-se levantadas questões sobre a falta de acesso a equipamentos urbanos de saúde, educação e lazer, sobre a baixa qualidade dos serviços de água, saneamento, energia e transporte público, mas pouco se fala sobre as questões de abastecimento e consumo. Nesta tese trazemos como foco a discussão sobre a presença do comércio e dos serviços nos empreendimentos habitacionais. Nas próximas sessões faremos uma discussão mais aprofundada desses casos, destacando a forma como as atividades econômicas são inseridas e as mudanças que provocam.

\section{Referências}

FERNANDES, José Alberto Rio; CACHINHO, Herculano; RIBEIRO, Carlos V. (coord.). Comércio tradicional em contexto urbano: dinâmicas de modernização e políticas públicas. Porto: Observatório do Comércio Português/Gabinete de Estudos de Desenvolvimento e Ordenamento de Território/Faculdade de Letras da Universidade do Porto - GEDES/FLUP, 2000. 166p. Disponível em: http://www.dgcc.pt/166.htm Acesso em 26 de outubro de 2015.

PRADO, André (2016). Ao fim da cidade. - Belo Horizonte : Editora UFMG.

SALGUEIRO, Teresa Barata (1996). Do comércio à distribuição. Rumos de uma mudança. Lisboa.

SANTOS, Milton. O espaço dividido: os dois circuitos da economia urbana dos países subdesenvolvidos. Rio de Janeiro: Francisco Alves, 1979. 345p.

VARGAS, Heliana Comin. Espaço terciário: o lugar, arquitetura e a imagem do comércio. São Paulo : Editora SENAC São Paulo, 2001. 